\title{
Promyelocytic leukemia zinc finger triggers ATP-binding cassette subfamily E member 1-mediated growth inhibition in breast cancer cells
}

\author{
BANDAR A. SULIMAN ${ }^{1,2}$ and SUHAD AL-YAHYA ${ }^{3}$ \\ ${ }^{1}$ BndrGene Medical Center, Research and Consultation Institute, Taibah University, Tayba, Medina 300, Saudi Arabia; \\ ${ }^{2}$ Center for Cancer Research, Hudson Institute of Medical Research, Clayton, VIC 3168, Australia; \\ ${ }^{3}$ Molecular Biomedicine Program, Research Center, King Faisal Specialist Hospital, Riyadh 12713, Saudi Arabia
}

Received March 18, 2017; Accepted December 19, 2017

DOI: $10.3892 / \mathrm{ol} .2018 .9207$

\begin{abstract}
The promyelocytic leukemia zinc finger (PLZF) protein is a transcription factor that is involved in a number of biological processes, including those regulating cellular growth; however, little is known regarding how it achieves its inhibitory effect in different cell and tissue types. It has previously been demonstrated that PLZF expression levels become diminished during the oncogenic transformation of certain tissue types and thus, may serve as a hallmark for tumor aggressiveness. To examine this in breast cancer, survival curves from available oncology databases were analyzed and demonstrated that PLZF expression was positively associated with increased survival in patients with breast cancer. The mRNA and protein levels of PLZF were also revealed to be associated with the tumorigenicity of four breast cancer cell lines. Since ATP-binding cassette subfamily E member 1 (ABCE1), also known as RNase L inhibitor, has been determined to be a target gene of PLZF, the present study also investigated whether the tumor suppressive effect of PLZF was associated with ABCE1 expression. PLZF was revealed to downregulate the expression of $\mathrm{ABCE} 1$ in vitro, which relieved the inhibitory effect of $\mathrm{ABCE} 1$ on the ribonuclease $\mathrm{L}$ enzyme. Finally, it was concluded that PLZF expression caused an ABCE1-mediated increase in cellular cytotoxicity, as demonstrated by a reduction in the proliferation rate of breast cancer cell lines. The results of the present study are important for understanding how PLZF exerts its final inhibitory actions in breast cancer cells, and potentially in other solid tumors, through the modulation of immunological pathways.
\end{abstract}

Correspondence to: Dr Bandar A. Suliman, BndrGene Medical Center, Research and Consultation Institute, Taibah University, 42 Janadah Bin Uayyah Road, Tayba, Medina 300, Saudi Arabia E-mail: bandar@bndrgene.med.sa

Key words: promyelocytic leukemia zinc finger, breast cancer, ATP-binding cassette subfamily E member 1, growth inhibition

\section{Introduction}

The promyelocytic leukemia zinc finger (PLZF) protein is a transcription factor belonging to the Krüppel-like zinc finger family (1). It regulates a variety of developmental and physiological pathways, and has been demonstrated to be involved in leukocyte differentiation and oncogenic transformation $(2,3)$. The potency and self-renewal abilities of many stem and early progenitor cells have also been linked to PLZF, which may maintain these phenotypic characteristics in certain cell lineages $(4,5)$. Since the identification of the PLZF/RAR $\alpha$ fusion protein in 1998 (6), several studies have linked the level of PLZF expression with the oncogenic transformation of numerous types of cancer cells $(7,8)$. Under normal physiological conditions, PLZF expression is minimally maintained to regulate both the cell cycle and cell differentiation potential through several accessory molecules, including cyclin A2, checkpoint suppressor 1, c-Myc and telomerase reverse transcriptase $(5,9,10)$. This low-level expression of PLZF may be further reduced to relieve the PLZF transcriptional control in cells, which ultimately enables tumorigenic cell transformation (11). In recent years, PLZF expression has also been implicated in the innate immune response. PLZF expression was demonstrated to control the clonal expansion and functional capacity of cluster of differentiation (CD)1d-restricted natural killer T cells (12), the induction of memory-like or innate $\mathrm{CD}^{+} \mathrm{T}$ cells (13) and, most notably, the positive regulation of a specific subset of interferon-stimulated genes (ISGs) in the interferon pathway (14). This complex and intriguing immunomodulatory function of PLZF is achieved through the stabilization of a histone deacetylase corepressor complex comprising HDAC3 and the p50 subunit of nuclear factor- $\kappa \mathrm{B}(15)$.

The 2-5A system is a well-characterized pathway that stimulates apoptosis when activated in cells. The system is triggered by the accumulation of double-stranded RNA in the cytoplasm caused by a viral infection or non-specific degradation. This, in turn, activates 2'-5'-oligoadenylate synthetase 1, an enzyme that converts ATP to short 2'-5'-linked oligoadenylates, known as 2-5A. 2-5A binds and activates the ribonuclease L enzyme (RNase L), which then cleaves 
single-stranded RNA, eventually leading to the degradation of ribosomal RNA (rRNA) and apoptosis (16). In a number of cells, the levels of RNase L are kept under tight spatial and temporal control during transcriptional and post-transcriptional events. This ensures that RNase L activity does not interfere with physiological cellular proliferation (17). RNase L and PLZF control viral pathogenesis through the induction of specific ISGs, which, when activated, stimulate various cellular proteins, including protein kinase $\mathrm{R}$, interferon regulatory factor 7, and signal transducer and activator of transcription 3 , to limit the synthesis of viral DNA and to promote the activation of apoptotic pathways in virally infected cells $(18,19)$.

The ATP-binding cassette subfamily E member 1 (ABCE1) protein is a member of the ATP-binding cassette (ABC) transporter family, and was originally described as an RNase L inhibitor (20), as well as a PLZF-targeted gene (21). ABCE1 expression was observed to be higher in lung cancer (22), retinoblastoma (23), melanoma (24) and colon cancer (25), compared with in normal cells, thereby demonstrating an opposite pattern to the expression signature of PLZF in cancer and in normal cells. Furthermore, the relatively high expression level of ABCE1 was implicated in the ongoing survival of these cancerous cells.

The aim of the present study was to explore the functional association between PLZF and RNase L. Therefore, the present study investigated whether ABCE1 inhibition, possibly through PLZF regulation, may induce the anti-proliferative effect of RNase L in a breast cancer cell line.

\section{Materials and methods}

Oncomine database. In order to evaluate the potential difference in PLZF expression between breast cancer and normal breast tissues, transcriptomic microarray data (reporter ID: 11-113531123, ILMN_1750496 and A_23_P104802) from the Oncomine cancer microarray database (www.oncomine. org) was utilized $(26,27)$. PLZF was added to the search inquiry, breast cancer was selected as the cancer type and the filter 'Cancer vs. Normal Analysis' was applied, using the database threshold values of odds ratio $>2.0$ and $\mathrm{P}<0.0001$. The PLZF mRNA copy number was analyzed in the following: 1,992 breast carcinoma and 144 normal breast samples from the Curtis dataset; 532 invasive breast carcinoma, 61 paired normal breast tissue and 3 paired metastatic samples from the TCGA dataset; and 786 invasive breast carcinoma, 702 paired blood-derived normal, 111 paired normal breast tissue and 3 paired metastatic samples from the TCGA molecular dataset. Table I demonstrates the number of each of the assessed tissue types observed in the TCGA and Curtis datasets. The datasets were classified into two main types: Normal tissue vs. different cancer types or based on the molecular classification of the tissue samples types [expression status of progesterone (PR), estrogen (ER) and human epidermal growth factor receptor 2 (HER2)]. The expression data were log-transformed and median-centered per array, and the standard deviation was normalized to one per array. Array data were used following adjustment of the threshold to those genes with a fold-change of 2 and a mean value with a significance level of $\mathrm{P}<0.0001$, using GraphPad Prism Version 7.00 for Windows (GraphPad Software, Inc., La Jolla, CA, USA).
Survival analysis. The hazard ratios for the expression levels of PLZF and ABCE1 in patients with breast cancer were estimated using the Kaplan-Meier method, and the log-rank test was used to compare the survival curves of patients grouped according to median PLZF and ABCE1 expression levels (low-medium and high-medium expression). Patient data were obtained from the Kaplan-Meier database, a comprehensive database containing microarray datasets from the Curtis and TCGA projects, among others. The distant metastasis-free survival (DMFS) and relapse-free survival (RFS) rates were determined as previously described (28). The number of patient samples used to determine DMFS was 1,769 , and the number of samples used to determine RFS was 3,955. The patient samples included all breast cancer molecular subtypes, including ER-, PR- and HER2-positive.

Cell culture. HeLa, 293T, MDA-MB-231, MCF7, MCF10 and MCF12 cells were obtained from the American Type Culture Collection (Manassas, VA, USA). The 293, HeLa, MDA-MB-231 and MCF7 cell lines were maintained in Dulbecco's modified Eagle's medium (DMEM; Gibco; Thermo Fisher Scientific, Inc., Waltham, MA, USA) containing $4.5 \mathrm{~g} / \mathrm{l}$ D-glucose, $10 \%$ fetal bovine serum (Sigma-Aldrich; Merck KGaA, Darmstadt, Germany), 2 mM L-Glutamine (Sigma-Aldrich; Merck KGaA) and $100 \mathrm{U} / \mathrm{ml}$ penicillin/streptomycin (Sigma-Aldrich; Merck $\mathrm{KGaA}$ ) in $5 \% \mathrm{CO}_{2}$ with $95 \%$ air at $37^{\circ} \mathrm{C}$. The MCF10 and MCF12 cell lines were maintained in DMEM/F12 (Gibco; Thermo Fisher Scientific, Inc.) containing $10 \%$ fetal bovine serum, $1 \%$ L-glutamine (Sigma-Aldrich; Merck KGaA), growth factors from the HuMEC Supplement kit (Thermo Fisher Scientific, Inc.) and $100 \mathrm{U} / \mathrm{ml}$ penicillin/streptomycin under the same conditions.

Reverse transcription-quantitative polymerase chain reaction ( $R T-q P C R)$. RNA was extracted from 293T, MCF-10, MCF-12, MCF7 and MDA-MB-231 cell lines by cell lysis using TRIzol (Thermo Fisher Scientific, Inc.) according to the manufacturer's protocol. Complementary DNA (cDNA) was synthesized using the SuperScript ${ }^{\circledR}$ III First-Strand Synthesis system (cat no. 18080-051; Invitrogen; Thermo Fisher Scientific, Inc.) by incubating $5 \mu \mathrm{g}$ total extracted RNA at $65^{\circ} \mathrm{C}$ for $5 \mathrm{~min}$ with the $10 \mathrm{mM}$ dNTP mixture and Oligo (dT) primers. The cDNA synthesis mix containing $25 \mathrm{mM} \mathrm{MgCl2,10x}$ RT buffer, 0.1 M DTT and SuperScript III Reverse Transcriptase enzyme was added to the RNA mix and incubated at $50^{\circ} \mathrm{C}$ for $50 \mathrm{~min}$ and the reaction was terminated by heating at $85^{\circ} \mathrm{C}$ for $5 \mathrm{~min}$. RT-qPCR was performed in triplicate using a Bio-Rad CFX96 ${ }^{\mathrm{TM}}$ Real-Time system (Bio-Rad Laboratories, Inc., Hercules, CA, USA) with oligonucleotides for PLZF forward, 5'-AACCACAAGGCT GACGCTGTA-3' and reverse, 5'-CATAGGTGCTGAAGT CCATGGA-3'; ABCE1 forward, 5'-TTGGTTGTGGGAAGT CGT-3' and reverse, 5'-GCTTATGTAGTTAATGGGAGGT-3'; HuR forward, 5'-GAGGCTCCAGTCAAAAACCA-3' and reverse, 5'-GTTGGCGTCTTTGATCACCT-3'; TTP forward, 5'-CGCTACAAGACTGAGCTAT-3' and reverse, 5'-GAGGTA GAACTTGTGACAGA-3'. The thermocycler conditions for the PCR were as follows: $55^{\circ} \mathrm{C}$ for $2 \mathrm{~min}$, then $95^{\circ} \mathrm{C}$ for $10 \mathrm{~min}$, $95^{\circ} \mathrm{C}$ for $15 \mathrm{sec}$ and $60^{\circ} \mathrm{C}$ for $1 \mathrm{~min}$ for a total of 45 cycles. The levels of target mRNA were normalized to that of $18 \mathrm{~S}$ 
Table I. Detailed numbers of samples for each of the TCGA and Curtis datasets obtained from the Oncomine cancer microarray database.

\begin{tabular}{|c|c|c|}
\hline Array & Cells & No. \\
\hline \multirow[t]{5}{*}{ TCGA type } & Normal tissue & 61 \\
\hline & Invasive breast carcinoma & 75 \\
\hline & Mixed lobular + ductal & 7 \\
\hline & Invasive ductal carcinoma & 392 \\
\hline & Invasive lobular carcinoma & 36 \\
\hline \multirow[t]{8}{*}{ TCGA molecular } & Normal tissue & 61 \\
\hline & ERBB2 +ve & 73 \\
\hline & ERBB2 -ve & 228 \\
\hline & PR -ve & 144 \\
\hline & PR +ve & 228 \\
\hline & ER -ve & 94 \\
\hline & $\mathrm{ER}+\mathrm{ve}$ & 274 \\
\hline & Triple -ve & 49 \\
\hline \multirow[t]{6}{*}{ Curtis type } & Normal tissue & 144 \\
\hline & Ductal BRCa in situ & 10 \\
\hline & Invasive breast carcinoma & 21 \\
\hline & Mixed lobular + ductal & 89 \\
\hline & Invasive ductal carcinoma & 1,556 \\
\hline & Invasive lobular carcinoma & 148 \\
\hline \multirow[t]{8}{*}{ Curtis molecular } & Normal tissue & 144 \\
\hline & ERBB2 +ve & 1743 \\
\hline & ERBB2 -ve & 249 \\
\hline & PR -ve & 943 \\
\hline & PR +ve & 1,049 \\
\hline & ER -ve & 440 \\
\hline & $\mathrm{ER}+\mathrm{ve}$ & 1,552 \\
\hline & Triple -ve & 250 \\
\hline
\end{tabular}

TCGA, The Cancer Genome Atlas; ERBB2, receptor tyrosine-protein kinase erbB2; PR, progesterone; ER, estrogen.

(reference ID: Hs03003631_g1; Thermo Fisher Scientific, Inc.) and were charted using the $2^{-\Delta \Delta C q}$ method (29). Results are expressed as the relative gene expression for each of the target genes, and are presented as the mean \pm standard deviation (SD).

Western blot analysis. In order to assess protein levels, cells were lysed in radioimmunoprecipitation assay buffer $[150 \mathrm{mM}$ $\mathrm{NaCl}, 50 \mathrm{mM}$ Tris (pH 8.0), 1.5 mM EDTA, 0.5\% Triton-X and $5 \%$ glycerol] containing $0.2 \mathrm{M}$ phenylmethylsulfonyl fluoride protease inhibitor (Roche Diagnostics, Basel, Switzerland). Protein quantification using Bradford protein assay (cat no. 500-0006; Bio-Rad Laboratories, Inc., Hercules, CA, USA) was performed as per the manufacture's recommendations by employing the Ultrospec 3100 pro $\mathrm{UV} /$ visible spectrophotometer Cell lysates for $\sim 30 \mu \mathrm{g}$ of total protein were resolved on a $10 \%$ gel, blocked with $5 \%$ milk in $1 \mathrm{X}$ PBS at $37^{\circ} \mathrm{C}$ for $1 \mathrm{~h}$, transferred to a nitrocellulose membrane (GenHunter Corporation, Nashville, TN,
USA), immunoblotted with primary antibodies (PLZF, cat no. sc-22839; Santa Cruz Biotechnology Inc., Dallas, TX, USA; $\beta$-actin, cat no. sc-69879; Santa Cruz Biotechnology Inc.; ABCE1, cat no. ab32270; Abcam, Cambridge, UK), incubated overnight (dilution, 1:500) at $4^{\circ} \mathrm{C}$ and detected using a horseradish peroxidase-conjugated $\operatorname{IgG}$ rabbit anti-mouse secondary antibody (dilution, 1:2,000; cat no. SC-2030; Santa Cruz Biotechnology, Inc.) at room temperature for $1 \mathrm{~h}$. Blots were developed using an SuperSignal West Pico Chemiluminescent Substrate (cat no. 34080; Thermo Fisher Scientific, Inc., Waltham, MA, USA) according to the manufacturer's protocol, and then imaged using a ChemiDoc ${ }^{\mathrm{TM}}$ XRS+ system v.2011 (Bio-Rad Laboratories, Inc.).

Real-time proliferation assay. Prior to the proliferation assay, MDA-MB-231 and MCF7 cells $\left(5 \times 10^{5}\right.$ cells/well) were cultured to $\sim 60 \%$ confluency on $6-\mathrm{cm}$ plates and transfected with $0.5 \mu \mathrm{g}$ pTRE3G-PLZF $+0.5 \mu \mathrm{g}$ Tet-On ${ }^{\circledR}$ constructs using $6 \mu 1$ Lipofectamine ${ }^{\circledR} 2000$ (Thermo Fisher Scientific, Inc.) as previously described (30). After $24 \mathrm{~h}$, the cells were washed with trypsin and seeded onto a 96-well plate at a density of $15 \times 10^{3}$ cells/well in full growth medium with or without $0.2 \mu \mathrm{g} / \mathrm{ml}$ doxycycline (Dox) for the proliferation assay. The plates were subsequently inserted into the xCELLigence ${ }^{\circledR}$ Real-Time Cell Analyzer instrument (ACEA Biosciences, San Diego, CA, USA), according to the manufacturer's protocols, in order to monitor cell proliferation.

Statistical analysis. Results were analyzed and graphed using GraphPad Prism ${ }^{\circledR}$ version 7.02 (GraphPad Software, Inc., La Jolla, CA, USA). Survival curves were compared between each group using the log-rank test; the data are reported as the mean mRNA expression of both PLZF and ABCE1. RT-qPCR results for PLZF mRNA were compared using one-way analysis of variance and a Holm-Sidak post-hoc test and are reported as the mean \pm standard deviation (SD). Real-time proliferation assay data are reported as the mean \pm SD. $\mathrm{P}<0.05$ was considered to indicate a statistically significant difference.

\section{Results}

PLZF expression is diminished in breast cancer tissues compared with in normal breast tissues. The expression of PLZF in breast cancer and normal tissue samples included in the Oncomine online microarray database was analyzed. Gene expression data were retrieved from the TCGA and Curtis databases (Table I) and were plotted to reveal the mean expression levels of PLZF. The mRNA levels of PLZF were found to be increased in normal tissues when compared with various types of adenocarcinoma and lobular carcinoma of the breast (Fig. 1). These results are similar to those of previous studies that identified an involvement of PLZF in the oncogenic transformation of prostate (31), colon (32) and leukemic cells (6).

PLZF expression is associated with survival in patients with breast cancer. The hazard ratio for the expression of PLZF in patients with breast cancer was calculated using Kaplan-Meier analysis and the log-rank test (Fig. 2). The results revealed that increased PLZF expression in patients with breast cancer was associated with prolonged survival compared 

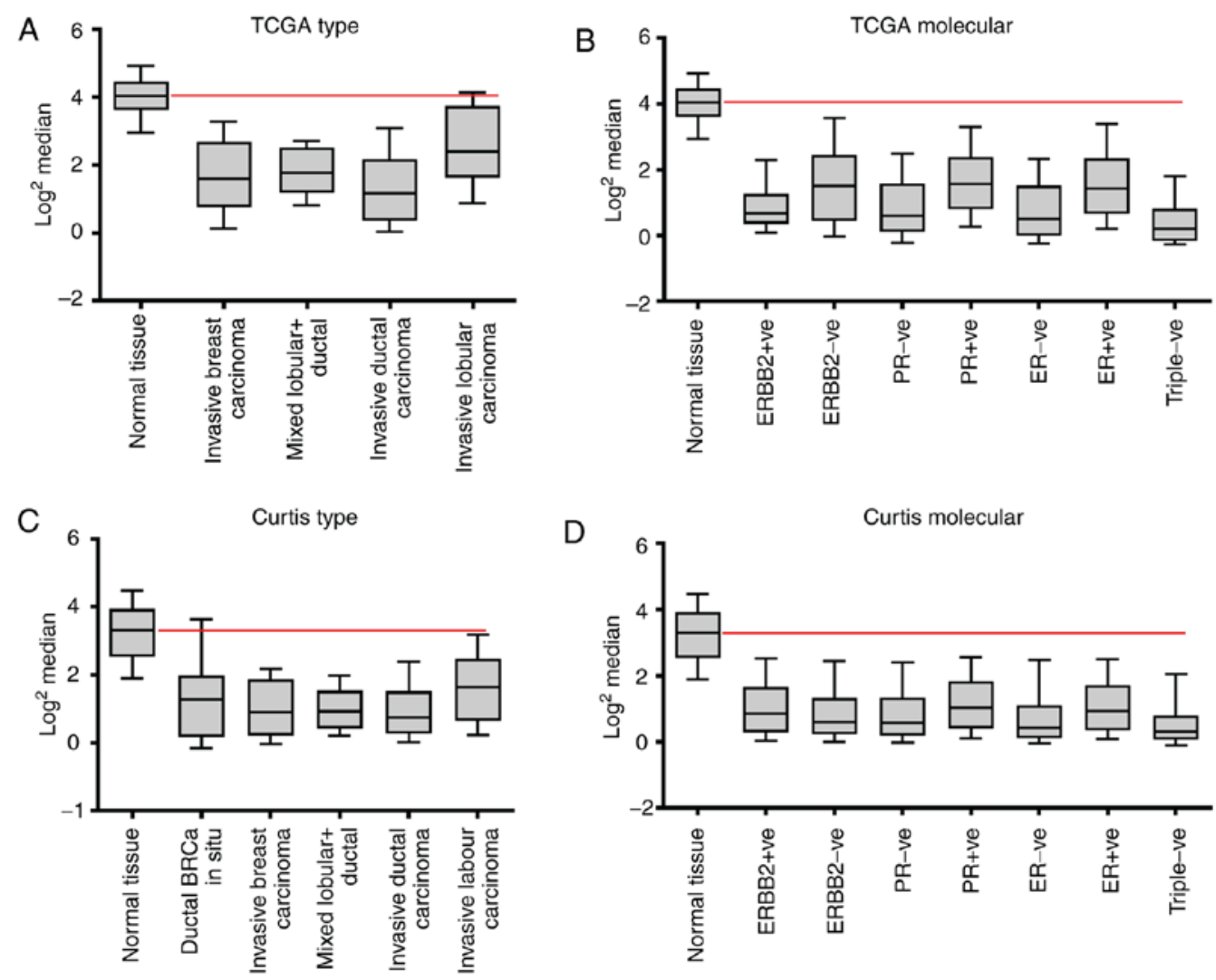

Figure 1. PLZF mRNA levels in normal breast tissue compared with different types of breast cancer based on samples from the (A) TCGA type, (B) TCGA molecular, (C) Curtis type and (D) Curtis molecular datasets. The mean expression levels of PLZF were significantly decreased in cancer tissues compared with in the normal breast tissues (mean PLZF levels in normal tissues are represented by the red line). PLZF, promyelocytic leukemia zinc finger; TGCA, The Cancer Genome Atlas; ERBB2, receptor tyrosine-protein kinase erbB-2; PR, progesterone receptor; ER, estrogen receptor.
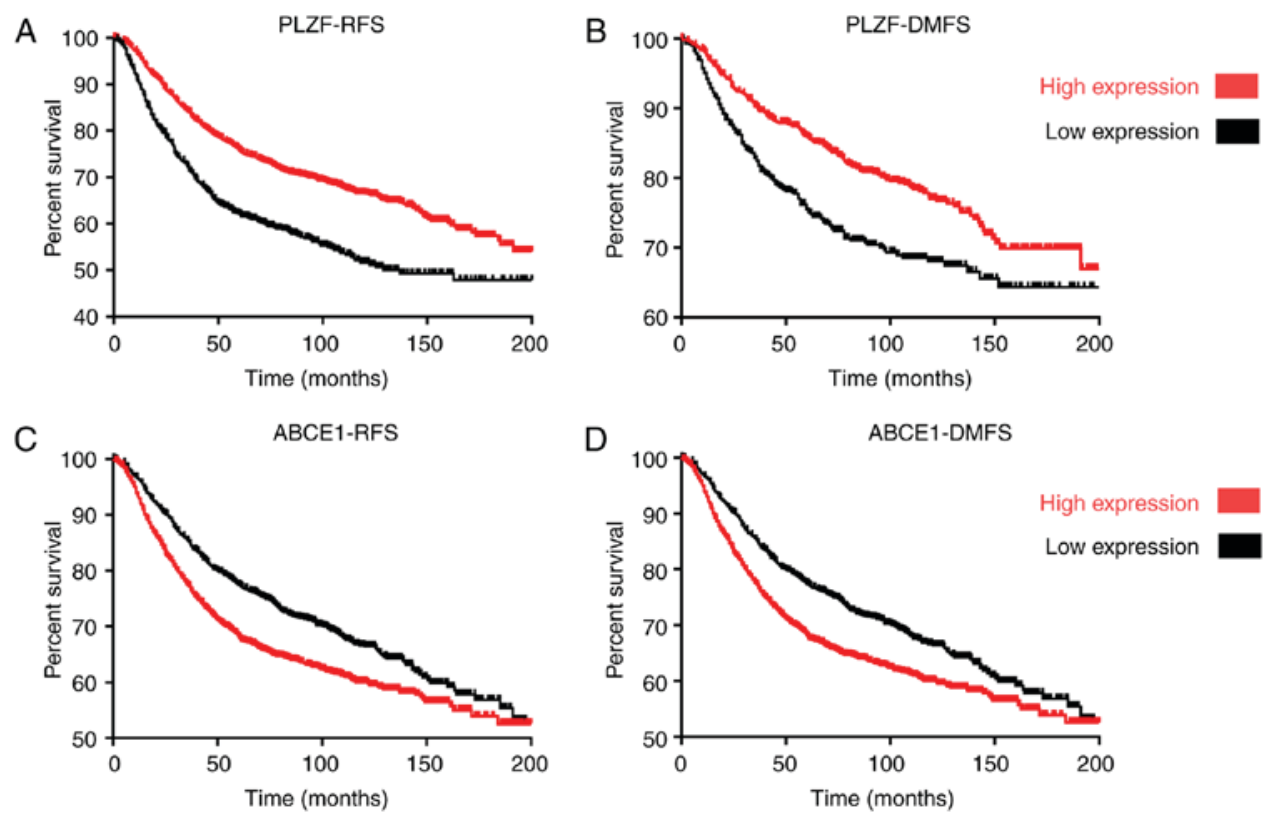

Figure 2. Survival curves for patients with breast cancer. Kaplan-Meier survival plots were produced to identify differences in the survival curves of patients with high and low levels of PLZF and ABCE1 expression. (A) RFS and (B) DMFS rates compared with PLZF expression; (C) RFS and (D) DMFS rates compared with ABCE1 expression. PLZF, promyelocytic leukemia zinc finger; ABCE1, ATP-binding cassette subfamily E member 1; RFS, relapse-free survival; DMFS, distant metastasis-free survival.

with patients with low PLZF expression. The DMFS rates of patients with low-medium PLZF expression were 78.16 and $69.33 \%$ compared with 87.94 and $79.58 \%$ in the patients with high-medium PLZF at 50 and 100 months, respectively 


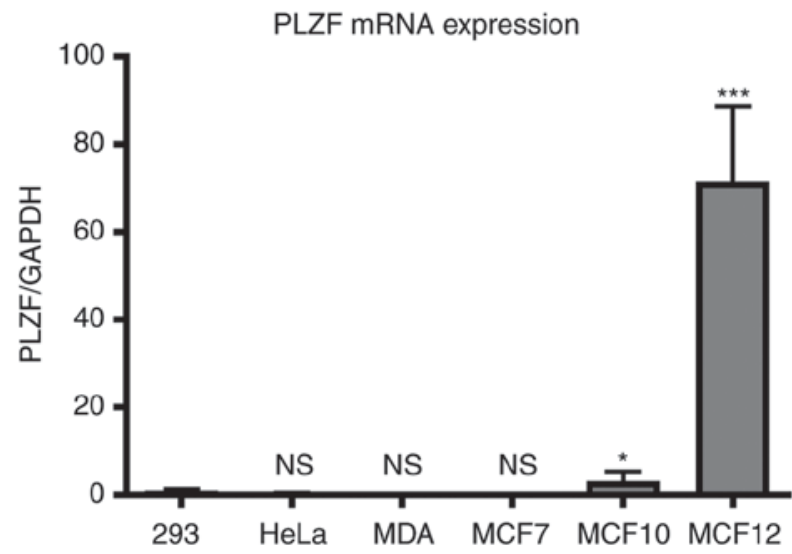

Figure 3. Reverse transcription-quantitative polymerase chain reaction assay of PLZF mRNA expression in breast cancer cells. Results are normalized to $18 \mathrm{~S}$ expression, and are reported as a fold-change relative to the levels of PLZF mRNA in 293 cells and are presented as the mean \pm standard deviation $(\mathrm{n}=3) .{ }^{*} \mathrm{P}<0.05 ;{ }^{* * *} \mathrm{P}<0.001$. PLZF, promyelocytic leukemia zinc finger; NS, not significant

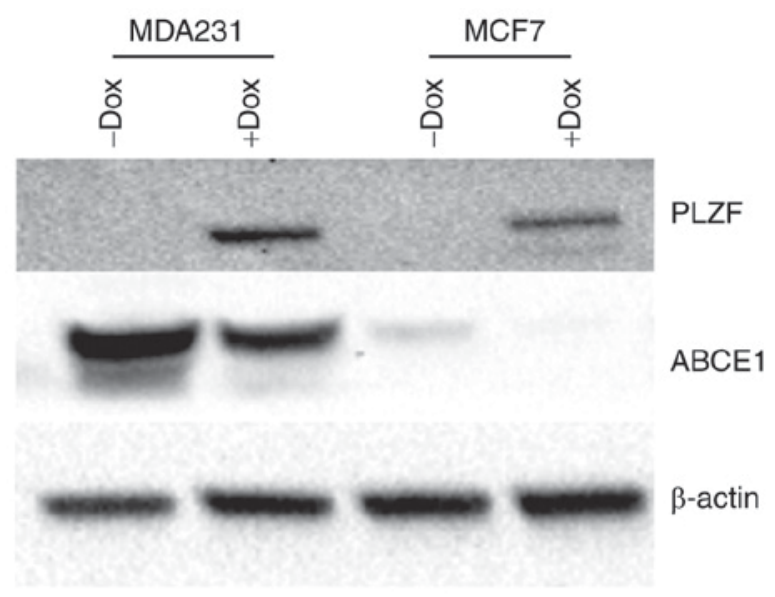

Figure 4. Western blot analysis of PLZF and ABCE1 expression in MDA-MB-231 and MCF-7 cells with or without the addition of $0.2 \mu \mathrm{g} / \mathrm{ml}$ Dox. Dox-induced PLZF expression inhibited ABCE1 protein expression in both cell lines after $24 \mathrm{~h}$. PLZF, promyelocytic leukemia zinc finger; ABCE1, ATP-binding cassette subfamily E member 1; Dox, doxycycline.

$\left(\mathrm{P}=9.1 \times 10^{-06}\right)$, and the RFS rates of patients with low-medium PLZF expression were lower, at 64.45 and $55.31 \%$ compared with 78.69 and $69.39 \%$ in patients with high-medium PLZF at 50 and 100 months, respectively $\left(\mathrm{P}=1 \times 10^{-16}\right)$.

Decreased ABCE1 expression in patients with breast cancer was associated with prolonged survival, as compared with patients with high ABCE1 expression. In patients with low-medium ABCE1 expression, the DMFS rates were 79.99 and $70.28 \%$ compared with 71.84 and $62.36 \%$ in patients with high-medium ABCE1 at 50 and 100 months, respectively $\left(\mathrm{P}=4.4 \times 10^{-04}\right)$, while the RFS rates in patients with low-medium ABCE1 expression were 79.91 and $70.26 \%$ compared with 71.14 and $62.37 \%$ in patients with high-medium PLZF at 50 and 100 months, respectively $\left(\mathrm{P}=2.3 \times 10^{-5}\right)$.

PLZF expression is associated with the tumorigenicity of breast cancer cell lines in vitro. The mRNA expression of PLZF is detectable in various cell types during their differentiation process, but this expression quickly becomes inhibited during the course of oncogenic transformation. The present study aimed to assess the expression of PLZF in the breast cancer cell lines MDA-MB-231 and MCF7, and in the breast basal epithelial cell lines MCF10 and MCF12. Cells were grown as aforementioned for $>48 \mathrm{~h}$ prior to total RNA extraction and cDNA synthesis. The basal expression of PLZF was revealed to be downregulated in the two cancer cell lines when compared with their epithelial cell equivalents (Fig. 3). Our previous study concerning PLZF expression in different cancer cells indicated that PLZF mRNA expression was higher in 293 cells compared with in HeLa cells (33). HeLa and 293 cell lines were included in the RT-qPCR assay of this study to compare the levels of PLZF mRNA expression in these two cell lines with corresponding levels in breast cancer cells. The results of the present study demonstrate that PLZF expression was markedly higher in MCF10 and MCF12 cells compared with in MCF7 and MDA-MB-231 cells, the latter of which retain the cytokeratin profiles of breast luminal cells, fail to form tumors in nude mice and exhibited no detectable PLZF mRNA expression (34). The fact that PLZF expression was almost undetectable in MDA-MB-231 and MCF7 cells rendered these cell lines suitable for overexpression experiments. Although MDA-MB-231 and MCF7 cells differ in terms of cell type (basal and luminal, respectively), the two are relatively tumorigenic and express numerous oncogenic phenotypes (35). These results demonstrated that PLZF expression is negatively associated with the tumorigenicity of breast cancer cell lines.

ABCE1 is implicated as a PLZF-targeted gene. Using an Affymetrix microarray chip, induction of the PLZF transcript has previously been demonstrated to downregulate a number of genes, including ABCE1 (21). Similarly, using Oncomine gene expression signatures, the present study compared the gene expression profiles of normal breast tissues with those of different breast cancer types and observed that ABCE1 was significantly overexpressed in cancer tissues when compared with in normal tissues (Table II). Notably, ABCE1 was revealed to be in the top $10 \%$ of overexpressed genes in both the invasive breast ductal carcinoma (TCGA Breast 2) and the invasive ductal carcinoma (Curtis Breast) datasets, and in the top $5 \%$ of overexpressed genes in the invasive ductal carcinoma (TCGA Breast) dataset. This was in agreement with our previous observation that the apparent loss of PLZF expression in cancer cells may cause an increase in ABCE1 expression in cancer tissues.

PLZF inhibits the expression of $A B C E 1$. PLZF is a transcriptional repressor that acts on a number of different signaling pathways and usually exerts its inhibitory effect through accessory molecules. To confirm that PLZF exerts the same transcriptional control over ABCE1, a PLZF Tet-On ${ }^{\circledR}$ system was used, as described previously (30), to induce PLZF expression in the cancer MDA-MB-231 and MCF7 cell lines. MDA-MB-231 cells lacked PLZF expression (both at the transcriptional and protein levels), as demonstrated in Figs. 3 and 4. It was observed that PLZF expression, induced 
Table II. Comparison of ABCE1 expression in breast cancer vs. normal tissues samples in the TCGA and Curtis datasets.

\begin{tabular}{lcccc}
\hline Comparison & P-value & Q-value & Odds ratio & Rank (\%) \\
\hline Invasive BRCa stroma vs. normal & $7.16 \times 10^{-70}$ & $9.63 \times 10^{-67}$ & 3.1 & Lowest 10 \\
Invasive ductal BRCa vs. normal & $1.48 \times 10^{-10}$ & $1.11 \times 10^{-7}$ & 10.1 & Lowest 10 \\
Invasive BRCa stroma vs. normal & $1.30 \times 10^{-8}$ & $5.37 \times 10^{-6}$ & 10.4 & Lowest 5
\end{tabular}

ABCE1, ATP-binding cassette subfamily E member 1.
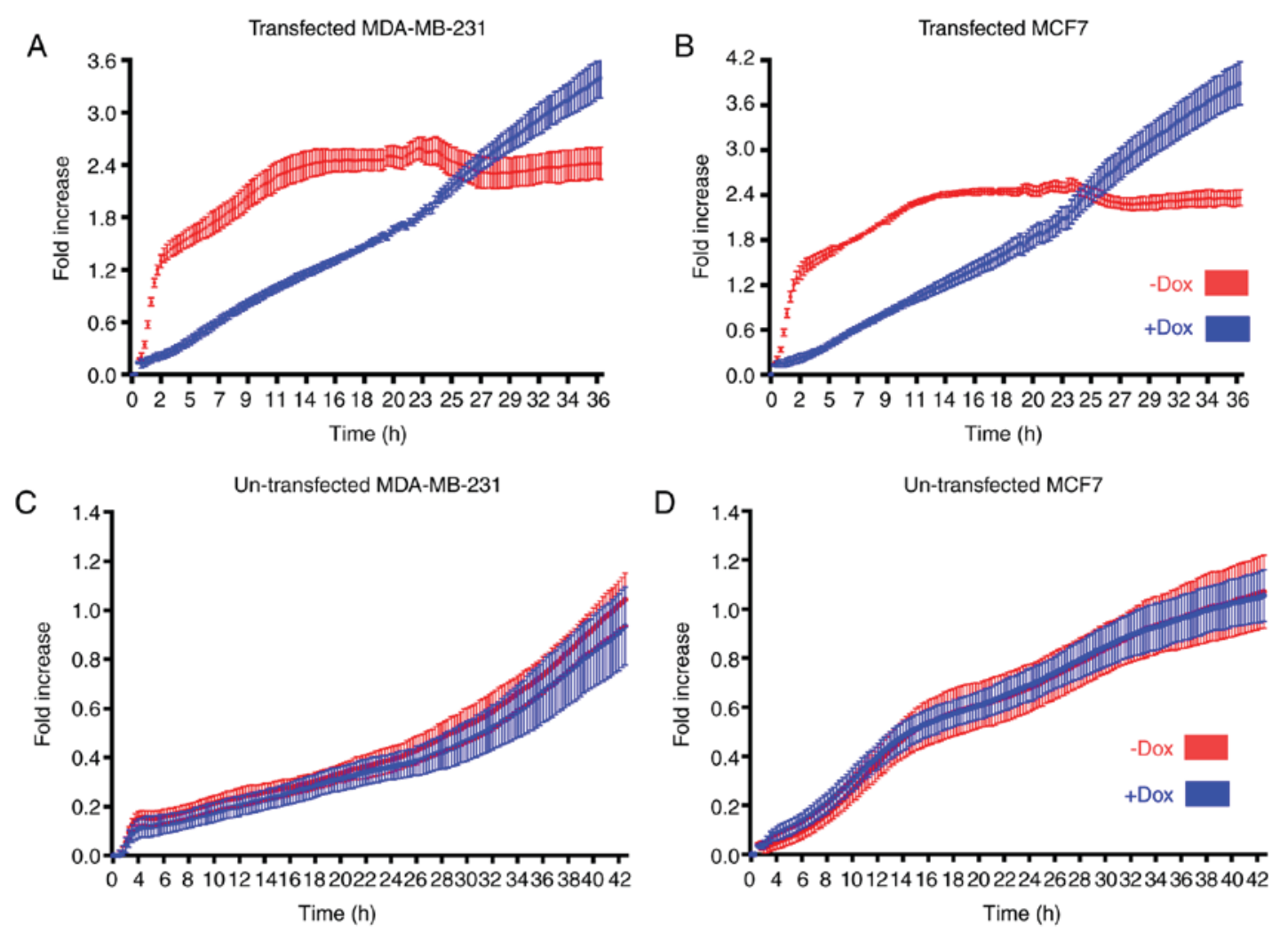

Figure 5. RTCA using an xCELLigence ${ }^{\circledast}$ RTCA instrument to identify the proliferation rates of (A) MDA-MB-231 and (B) MCF-7 cells transfected with the PLZF tet-on system and incubated in growth medium with $0.2 \mu \mathrm{g} / \mathrm{ml}$ Dox (blue) or without Dox (red) for $36 \mathrm{~h}$. Un-transfected (C) MDA-MB-231 and (D) MCF-7 cells incubated in growth medium with $0.2 \mu \mathrm{g} / \mathrm{ml}$ Dox (red) or without Dox (blue) for $42 \mathrm{~h}$. RTCA, real-time cellular analysis; PLZF, promyelocytic leukemia zinc finger; Dox, doxycycline.

by overnight treatment with $0.2 \mu \mathrm{g} / \mathrm{ml}$ Dox, markedly downregulated ABCE1 protein expression (Fig. 4).

PLZF expression induces an ABCE1-mediated inhibition of cellular proliferation in breast cancer cells. Although Dox treatment has been reported to alter the genetic signature of a number of common cancer cell lines (36), its effect on the proliferation capacity of these cells is less significant than the marked effect observed in the present study. Furthermore, the addition of $0.2 \mu \mathrm{g} / \mathrm{ml}$ Dox to the culture medium in a study using Dox in gene-regulated assays demonstrated that there was no significant effect compared with the vehicle control (37).

Through real-time cell analysis using an xCELLigence ${ }^{\circledR}$ RTCA instrument, a significant decrease in the proliferation capacity of MDA-MB-231 and MCF-7 cells, which were previously transfected with the PLZF tet-on system, was observed following treatment with $0.2 \mu \mathrm{g} / \mathrm{ml}$ Dox. Dox-induced
PLZF expression markedly diminished the cellular proliferation capability within $36 \mathrm{~h}$ of treatment (Fig. 5A and B). MDA-MB-231 and MCF-7 cells that were not treated with Dox continued to proliferate in a logarithmic manner consistent with normal physiological proliferation behavior in vitro. The same number of non-transfected MDA-MB-231 and MCF-7 cells were then cultured with or without $0.2 \mu \mathrm{g} / \mathrm{ml}$ Dox. No significant difference was observed in the two proliferation curves over $48 \mathrm{~h}$ (Fig. 5C and D). The results of the present study demonstrated that PLZF expression causes an ABCE1-mediated inhibition of the proliferation of breast cancer cell lines.

\section{Discussion}

Transcription factors serve an essential role in the molecular regulation of protein expression. Numerous types of cancer cells reach their oncogenic state through alterations in their 
protein signature $(4,5)$. This is commonly achieved by the transcriptional inhibition of safeguard proteins (which safeguard against cell cycle override; for example, tumor protein p53), which would otherwise prevent the cell from undergoing continuous division and from evading apoptosis $(5,9,10)$. PLZF has been previously demonstrated to be a tumor suppressor gene in certain types of cancer (11). However, the exact manner of its inhibitory effect in different cellular environments has yet to be elucidated.

Using a number of microarray datasets, the mRNA expression of PLZF was found to be associated with the survival rate of patients with breast cancer. Higher PLZF expression not only corresponded with a better survival rate in these patients, it was also negatively associated with the tumorigenicity of breast cancer cell lines commonly used in cancer research. PLZF, like other transcription factors, exerts its biological effects through numerous downstream targets. In turn, these targets participate in a number of other signaling pathways, which further complicates our understanding of how each molecule or protein is involved in the oncogenic transformation of specific cell types.

The RNase L inhibitor ABCE1 has previously been identified as a PLZF-targeted gene $(18,19)$. Using western blot analysis to quantify protein expression, it was observed that PLZF downregulated ABCE1 expression in the breast cancer cell lines used in the present study. This inhibition of ABCE1 likely caused RNase L upregulation in the breast cancer cells, leading to the diminished proliferation of cells. PLZF exerts a chromatin-stabilization effect that enables a basal activity state of early response genes to be established, alongside its ability to control the inflammatory reaction (14). Therefore, PLZF may be a useful modulator capable of differentially targeting certain signaling pathways that are yet to be investigated in an oncological context, but which may ultimately change the overall phenotype of tumors. The findings of the present study are important for understanding how PLZF exerts its final inhibitory actions in breast cancer cells, and potentially in other solid tumors, through the modulation of immunological pathways. Furthermore, these results may pave the way for further studies into the targeting of PLZF as an approach to limiting the oncogenic transformation and aggressiveness of associated cancer types.

\section{Acknowledgements}

The authors would like to thank Professor Khalid Abu Khabar (King Faisal Specialist Hospital and Research Centre) for supplying the required reagents and for providing support with the databases.

\section{Availability of data and materials}

All data generated or analyzed during this study are included in this published article.

\section{Authors' contributions}

BAS and SAY designed the research, conducted the experiments, analyzed the data, and drafted the manuscript. All authors read and approved the final manuscript.

\section{Ethics approval and consent to participate}

Not applicable.

\section{Consent for publication}

Not applicable.

\section{Competing interests}

The authors declare that they have no competing interests.

\section{References}

1. Chen Z, Brand NJ, Chen A, Chen SJ, Tong JH, Wang ZY, Waxman $S$ and Zelent A: Fusion between a novel Krüppel-like zinc finger gene and the retinoic acid receptor-alpha locus due to a variant $\mathrm{t}(11 ; 17)$ translocation associated with acute promyelocytic leukaemia. EMBO J 12: 1161-1167, 1993.

2. Li X, Peng H, Schultz DC, Lopez-Guisa JM, Rauscher FJ III and Marmorstein R: Structure-function studies of the BTB/POZ transcriptional repression domain from the promyelocytic leukemia zinc finger oncoprotein. Cancer Res 59: 5275-5282, 1999.

3. Rho SB, Park YG, Park K, Lee SH and Lee JH: A novel cervical cancer suppressor 3 (CCS-3) interacts with the BTB domain of PLZF and inhibits the cell growth by inducing apoptosis. FEBS Lett 580: 4073-4080, 2006.

4. Park I, Qian D, Kiel M, Becker MW, Pihalja M, Weissman IL, Morrison SJ and Clarke MF: Bmi-1 is required for maintenance of adult self-renewing haematopoietic stem cells. Nature 423: 302-305, 2003

5. Costoya JA, Hobbs RM, Barna M, Cattoretti G, Manova K, Sukhwani M, Orwig KE, Wolgemuth DJ and Pandolfi PP: Essential role of Plzf in maintenance of spermatogonial stem cells. Nat Genet 36: 653-659, 2004.

6. Yeyati PL, Shaknovich R, Boterashvili S, Li J, Ball HJ Waxman S, Nason-Burchenal K, Dmitrovsky E, Zelent A and Licht JD: Leukemia translocation protein PLZF inhibits cell growth and expression of cyclin A. Oncogene 18: 925-934, 1999.

7. Felicetti F, Errico MC, Bottero L, Segnalini P, Stoppacciaro A, Biffoni M, Felli N, Mattia G, Petrini M, Colombo MP, et al: The promyelocytic leukemia zinc finger-microRNA-221/-222 pathway controls melanoma progression through multiple oncogenic mechanisms. Cancer Res 68: 2745-2754, 2008.

8. Hurst DR, Edmonds MD, Scott GK, Benz CC, Vaidya KS and Welch DR: Breast cancer metastasis suppressor 1 up-regulates miR-146, which suppresses breast cancer metastasis. Cancer Res 69: 1279-1283, 2009.

9. Bernardo MV, Yelo E, Gimeno L, Campillo JA and Parrado A: Identification of apoptosis-related PLZF target genes. Biochem Biophys Res Commun 359: 317-322, 2007.

10. Cheung M, Pei J, Pei Y, Jhanwar SC, Pass HI and Testa JR: The promyelocytic leukemia zinc-finger gene, PLZF, is frequently downregulated in malignant mesothelioma cells and contributes to cell survival. Oncogene 29: 1633-1640, 2010.

11. Suliman BA, Xu D and Williams BR: The promyelocytic leukemia zinc finger protein: Two decades of molecular oncology. Front Oncol 2: 74, 2012.

12. Savage AK, Constantinides MG, Han J, Picard D, Martin E, Li B, Lantz $\mathrm{O}$ and Bendelac A: The transcription factor PLZF directs the effector program of the NKT cell lineage. Immunity 29: 391-403, 2008.

13. Weinreich MA, Odumade OA, Jameson SC and Hogquist KA: PLZF+ T cells regulate memory-like CD8+ T cell development. Nat Immunol 11: 709-716, 2010.

14. Xu D, Holko M, Sadler AJ, Scott B, Higashiyama S, Berkofsky-Fessler W, McConnell MJ, Pandolfi PP, Licht JD and Williams BR: Promyelocytic leukemia zinc finger protein regulates interferon-mediated innate immunity. Immunity 30 : 802-816, 2009.

15. Sadler AJ, Suliman BA, Yu L, Yuan X, Wang D, Irving AT, Sarvestani ST, Banerjee A, Mansell AS, Liu JP, et al: The acetyltransferase HAT1 moderates the NF- $\kappa \mathrm{B}$ response by regulating the transcription factor PLZF. Nat Commun 6: 6795, 2015. 
16. Li XL, Blackford JA, Judge CS, Liu M, Xiao W, Kalvakolanu DV and Hassel BA: RNase-L-dependent Destabilization of Interferon-induced mRNAs. A role for the 2-5A system in attenuation of the interferon response. J Biol Chem 275: 8880-8888, 2000.

17. Zhou A, Paranjape J, Brown TL, Nie H, Naik S, Dong B, Chang A, Trapp B, Fairchild R, Colmenares C and Silverman RH: Interferon action and apoptosis are defective in mice devoid of 2',5'-oligoadenylate-dependent RNase L. EMBO J 16: 6355-6363, 1997.

18. Fernandes J: Oncogenes: The passport for viral oncolysis through PKR inhibition. Biomark Cancer 8: 101-110, 2016.

19. He Z, Jiang J, Kokkinaki M, Tang L, Zeng W, Gallicano I, Dobrinski I and Dym M: MiRNA-20 and mirna-106a regulate spermatogonial stem cell renewal at the post-transcriptional level via targeting STAT3 and Ccnd1. Stem cells 31: 2205-2217, 2013.

20. Bisbal C, Martinand C, Silhol M, Lebleu B and Salehzada T: Cloning and characterization of a RNAse L inhibitor. A new component of the interferon-regulated 2-5A pathway. J Biol Chem 270: 13308-13317, 1995.

21. McConnell MJ, Chevallier N, Berkofsky-Fessler W, Giltnane JM, Malani RB, Staudt LM and Licht JD: Growth suppression by acute promyelocytic leukemia-associated protein PLZF is mediated by repression of c-myc expression. Mol Cell Biol 23: 9375-9388, 2003.

22. Ren Y, Li Y and Tian D: Role of the ABCE1 gene in human lung adenocarcinoma. Oncol Rep 27: 965-970, 2012.

23. Hendig D, Langmann T, Zarbock R, Schmitz G, Kleesiek K and Götting C: Characterization of the ATP-binding cassette transporter gene expression profile in Y79: A retinoblastoma cell line. Mol Cell Biochem 328: 85-92, 2009.

24. Heimerl S, Bosserhoff AK, Langmann T, Ecker J and Schmitz G: Mapping ATP-binding cassette transporter gene expression profiles in melanocytes and melanoma cells. Melanoma Res 17: 265-273, 2007.

25. Hlavata I, Mohelnikova-Duchonova B, Vaclavikova R, Liska V, Pitule P, Novak P, Bruha J, Vycital O, Holubec L, Treska V, et al: The role of $\mathrm{ABC}$ transporters in progression and clinical outcome of colorectal cancer. Mutagenesis 27: 187-196, 2012.

26. Rhodes DR, Yu J, Shanker K, Deshpande N, Varambally R, Ghosh D, Barrette T, Pandey A and Chinnaiyan AM: ONCOMINE: A cancer microarray database and integrated data-mining platform. Neoplasia 6: 1-6, 2004.
27. Glass D, Viñuela A, Davies MN, Ramasamy A, Parts L, Knowles D, Brown AA, Hedman AK, Small KS, Buil A, et al: Gene expression changes with age in skin, adipose tissue, blood and brain. Genome Biol 14: R75, 2013.

28. Bewick V, Cheek L and Ball J: Statistics review 12: Survival analysis. Critical Care 8: 389-394, 2004.

29. Livak KJ and Schmittgen TD: Analysis of relative gene expression data using real-time quantitative PCR and the 2(-Delta Delta C(T)) method. Methods 25: 402-408, 2001

30. Suliman BA: The generation of a ZBTB16-inducible expression system in the ACHN adenocarcinoma cell line. J Taibah Univ Medical Sci 10: 359-364, 2015.

31. Kikugawa T, Kinugasa Y, Shiraishi K, Nanba D, Nakashiro KI, Tanji N, Yokoyama M and Higashiyama S: PLZF regulates Pbx1 transcription and Pbx1-HoxC8 complex leads to androgen-independent prostate cancer proliferation. Prostate 66: 1092-1099, 2006.

32. Mariani F, Sena P, Magnani G, Mancini S, Palumbo C, Ponz de Leon M and Roncucci L: PLZF expression during colorectal cancer development and in normal colorectal mucosa according to body size, as marker of colorectal cancer risk. ScientificWorldJournal 2013: 630869, 2013.

33. Bandar Ali S: The role of PLZF in the TLR-mediated inflammatory response and the oncogenic characteristics of renal cell carcinoma, 2017.

34. Paine TM, Soule HD, Pauley RJ and Dawson PJ: Characterization of epithelial phenotypes in mortal and immortal human breast cells. Int J Cancer 50: 463-473, 1992.

35. Nagaraja G, Othman M, Fox B, Alsaber R, Pellegrino C, Zeng Y, Khanna R, Tamburini P, Swaroop A and Kandpal RP: Gene expression signatures and biomarkers of noninvasive and invasive breast cancer cells: Comprehensive profiles by representational difference analysis, microarrays and proteomics. Oncogene 25: 2328-38, 2006

36. Xie J, Nair A and Hermiston TW: A comparative study examining the cytotoxicity of inducible gene expression system ligands in different cell types. Toxicology In Vitro 22: 261-266, 2008.

37. Onoda T, Ono T, Dhar DK, Yamanoi A, Fujii T and Nagasue N: Doxycycline inhibits cell proliferation and invasive potential: Combination therapy with cyclooxygenase-2 inhibitor in human colorectal cancer cells. J Lab Clin Med 143: 207-216, 2004.

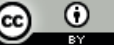

This work is licensed under a Creative Commons Attribution 4.0 International (CC BY 4.0) License. 